\title{
Statewide Rural-Urban Bus Travel Demand and Network Evaluation: An Application in Tennessee
}

\author{
Hongtai Yang and Christopher R. Cherry \\ University of Tennessee-Knoxville
}

\begin{abstract}
This paper examines the characteristics of intercity bus riders within Tennessee and proposes methods to identify service gaps and prioritize network expansion, particularly focusing on rural-urban connections. Data were collected through an on-board survey and compared with intercity auto trips. Compared to personal auto users, intercity bus riders are more likely to be of minority races, unemployed, unable to drive, and from low-income households. Five demand levels were determined based on the population distribution with these characteristics. The service areas of existing bus stops were identified and compared with the high demand areas. The result shows that an insufficient number of stops are located in high demand area. Still, approximately 80 percent of stops connect to meaningful destinations such as hospitals. The results imply that bus stations are well-connected to destinations but poorly connected to potential riders. Changes to the current network could better cover high-demand areas.
\end{abstract}

\section{Introduction}

Scheduled intercity bus service declined by one-third between 1960 and 1980, and remaining service declined by half between 1980 and early 2006 in the United States (Schwieterman et al. 2007). With rising travel demand, escalating gasoline prices, 
and Federal Transit Administration (FTA) 5311(f) funding for intercity bus agencies to provide or continue service, the industry is beginning to see more ridership. In recent years, fixed-route and scheduled intercity bus service have experienced a renaissance. It was rated as the fastest-growing mode of intercity transportation, outpacing air and rail transportation in 2010 (Schwieterman and Fischer 2010). In Tennessee, an Intercity Bus Demonstration Program was implemented in 2008 in response to growing public intercity travel needs, particularly focused on connecting rural and urban areas. There is a growing number of fixed-route, scheduled intercity bus services in the state. In the context of this study, we focus on intercity buses operating within the state of Tennessee and not directly connecting to different states, even though they do feed interstate bus and air terminals. In general, the intercity bus services described in this paper are short-haul buses that connect rural regions with urban centers.

Approaches to modeling intercity and interstate travel have evolved over the decades. Several early papers applied econometric methods to investigate choice behavior (Ashiabor, Baik, and Trani 2007; Koppelman 1989; Morrison and Winston 1985; Stopher and Prashker 1976). Because of jurisdictional and funding boundaries, within-state rural transit is a special class of transit service that deserves special study. However, little contemporary research has been directed to within-state intercity bus services, particularly in the context of recent demographic changes and growth in demand. This paper investigates emerging rural-urban bus travel patterns. A framework is presented to supplement locally-collected bus rider data with general long-distance travel described in the National Household Travel Survey (NHTS) (representing very few intercity bus trips) and apply this method to the Tennessee bus network. The paper describes results of intercity bus rider surveys that explore rider and trip characteristics of intercity bus users and contrasts those results with intercity car travel from the NHTS. Those data were used to estimate and map high demand regions to provide a framework to analyze rural-urban intercity bus service and connectivity between potential riders and their destinations. The paper highlights previous relevant research in the next section, followed by a description of the survey methods.

\section{Previous Intercity Bus Studies}

\section{Intercity Travel Demand Model Review}

A few papers have presented mode choice modeling approaches for intercity surface travel. Ashiabor et al. (2007) reviewed disaggregate nationwide travel demand 
modes developed by Stopher and Prashker (1976), Grayson (1981), Morrison and Winston (1985), and Koppelman (1989) between 1976 and 1990. All four models used versions of National Travel Surveys (NTS), and they included bus as one of the transportation modes. The fifth attempt to model nationwide travel demand was carried out by Ashiabor et al. (2007), who developed a logit model based on 1995 American Travel Survey (ATS). However, both the 1977 NTS and 1995 ATS collected information only on trips of 100 miles or more, eliminating intercity trips shorter than 100 miles, which includes most in-state Tennessee intercity bus trips.

Fravel et al. (2011), in "Toolkit For Estimating Demand For Rural Intercity Bus Service" (TCRP Report 147), introduced a toolkit to estimate demand for rural intercity bus corridors. The toolkit includes two demand estimation models, a regression model and a trip rate model, both of which give more accurate results for current rural intercity bus services than previous efforts to model intercity bus demand. However, this toolkit has limitations that cannot be used for regional transit, which includes much of the rural-urban bus service.

A Minnesota intercity bus network study (KFH Group 2010) chose five transitdependent population characteristics to profile persons who rely on transit. Potential intercity bus needs were identified by comparing the locations served by the current network with the locations in Minnesota that have concentrations of persons more likely to rely on public transportation. The limitation with the Minnesota study is that characteristics of transit-dependent populations, which are mainly determined by urban public transit riders, could differ from intercity bus rider characteristics. This means that using transit-dependent population characteristics to determine areas of high intercity bus needs could introduce some bias. Also, identifying locations with high intercity bus need is not enough to evaluate an intercity bus network; how well the network connects to the destinations also should be studied. This paper extends the Minnesota study by comparing the characteristics of Tennessee rural-urban intercity bus riders to the characteristics of general travelers to obtain specific characterizations of potential riders.

\section{Intercity Bus Riders Characteristics}

A 1981 Tennessee intercity bus study (J. R. Wilburn and Associates 1981) developed a survey to ascertain a profile of passengers. It was conducted for a 24-hour period at several bus terminal locations. The survey results showed that a typical intercity bus passenger is age 16-25, uses the bus once a year to visit friend and relatives, travels over 10 miles by auto to get to and from the terminals, and come from households with total income of $\$ 7,501-\$ 15,000$ per year, which was lower 
than the 1981 national median household income of $\$ 18,033$. Findings indicated some variance in automobile ownership between cities. In Chattanooga, Memphis, and Nashville, most respondents indicated that they owned one automobile, while in Jackson and Knoxville, most respondents indicated that they did not own an automobile.

The Bureau of Transportation Statistics (BTS) 1995 rider study (Bureau of Transportation Statistics 1997) concluded that intercity bus riders are more likely to be persons ages 65 years and older, female, minority, and less educated, who live in households with low income and no personal use vehicle available. Although the BTS study provides a good description of long distance intercity bus rider characteristics, the study parallels the scope of the ATS, focusing on people who travel more than 100 miles.

Although these two studies have given a comprehensive view of intercity travel mode choice modeling and intercity bus rider characteristics, both are obsolete, and there is a gap in the literature on within-state long distance bus traveler characteristics, particularly trips linking rural areas with urban centers. Therefore, it is crucial to obtain information about intrastate long-distance travelers in order to determine their characteristics and identify the areas of potential demand. This paper addresses this gap and evaluates how rural-urban intercity bus rider population demographics are different from overall intercity traveling populations.

In addition to identifying high intercity bus demand areas and assessing the connectivity of current network to those areas, methods to evaluate the connections of riders to destinations are introduced using a Geographic Information System (GIS) framework. This study proposes a framework to evaluate existing intercity bus network effectiveness at connecting probable intercity bus riders to destinations and introduces ways to improve these connections. Although this study observes only Tennessee rural-urban intercity trips and determined most to be less than 100 miles, it is reasonable to assume, because of similar state geography, that other states also have many intercity trips that are less than 100 miles.

\section{Survey Methods}

To gather information from intercity bus users, a questionnaire was developed for riders of each intercity bus route supported by the FTA 5311(f) program that funds fixed-route intercity bus service. This group included 5 rural transit companies ( 3 human resource agencies and 2 private service providers) that provide 756 
route-miles of service in Tennessee. The surveys were conducted between May 1 and August 21, 2010. Intercity bus passengers were asked about their trips and to provide personal information. The survey explored trip and demographic characteristics.

Two survey methodologies were used. First, passengers are approached and interviewed by surveyors at different bus stops or onboard. This type of survey has a high response rate, a high quality of data collected, and allows surveyors to collect open-ended observations from riders. However, a considerable drawback of this method is that it has high cost for interviewers, owing to low bus service frequency, dispersed bus stop locations, and relatively few riders. A pilot intercept survey was performed to test the method. During the two-day pilot, 27 riders were interviewed.

Another survey method distributed questionnaires to bus riders with the help of the driver. Survey packages were distributed to the transit agencies, and drivers gave the surveys to boarding riders along with a pencil and mail-back envelope. This survey method had a relatively low response rate, but it greatly increased the cost-effectiveness of the data collection. Using this method, 446 questionnaires were sent out and 92 were returned ( $21 \%$ response rate). The true response rate is somewhat uncertain because we were unable to confirm that all surveys were actually distributed to passengers. Also, because of lack of supervision, some surveys were returned incomplete.

\section{Survey Analysis and Comparison Results}

Considering the low number of intercity bus trips recorded in the 2009 NHTS (i.e., nationwide, only 48 trips made by intercity bus out of 62,968 trips of greater than 30 miles), it is difficult to model intercity bus travel from this dataset. Indeed, the NHTS does not record any trips in Tennessee made by intercity bus, making it impossible to follow traditional mode-choice modeling strategies. Therefore, we adopted an alternative approach to estimate potential intercity bus rider demand. The data for all intercity trips made in Tennessee by all modes were extracted from NHTS. We supplemented the NHTS data with our on-board survey data. Comparing data in our survey to the dataset extracted from NHTS illustrates the diverging characteristics of intercity bus riders and their trips from car-based transportation. Furthermore, intercity bus rider attributes can serve as a reference to determine the number of potential intercity bus riders in each census tract in Tennessee; this 
was converted to estimate likely intercity bus rider population densities. Identifying these areas of population density helped to determine the areas with higher potential intercity bus demand.

The characteristics of intercity bus riders and trips were summarized from the survey responses and compared with those of intercity car trips of the same range of travel distance, extracted from the 2010 NHTS. For our survey, recorded trip lengths range from 6 miles to 162.5 miles ( 2 trips were recorded at less than 30 miles, which may be the result of misunderstanding the survey questions or a writing error). We defined the shortest length of an intercity trip as 30 miles, while the upper limit was rounded to 170 miles. The intercity bus trip distance includes distance from rider origin to boarding bus stop, travel distance on the bus, and distance from alighting stop to destination. A geographic criterion was used to filter the data from NHTS so that only trips made within Tennessee were selected. This was done to ensure consistency with the scope and administrative boundaries of the study. Because the trip origin and destination are unknown in the NHTS data, the state in which a survey responder's household is located was adopted as an alternative means to select the trips made in Tennessee.

The filtered NHTS dataset included 1,116 intercity trips distributed among all modes in Tennessee. Figure 1 shows that 1,075 trips were made by non-public transportation and no trips were made by intercity bus. Of these trips, 129 were made by private vans, which could include commuter vanpools.

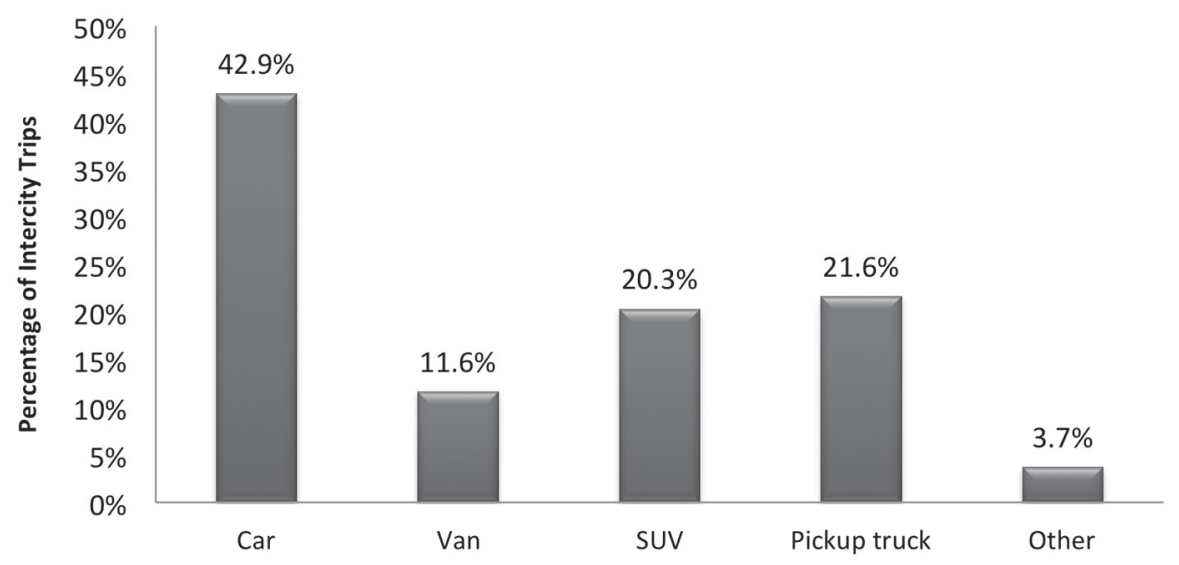

Figure 1. Transportation Mode Choice Percentage of NHTS Intercity Trips 
In addition to transportation mode choice, 11 trip and rider characteristics were compared, including race, gender, age, employment status, ability to drive, household annual income, household size, number of vehicles available in household, education level, trip purpose, and trip distance. We assumed that these 11 characteristics influence a traveler's mode choice and, therefore, are included in both the NHTS and our survey.

Comparing the NHTS intercity trips (mostly car) in Tennessee with our dataset revealed significant differences in all variables with the exception of gender, shown in Table 1.

\section{Table 1. Demographic Comparison between NHTS and Intercity Bus Trips}

\begin{tabular}{|c|c|c|c|c|}
\hline Variable Name & Category & $\begin{array}{c}\text { NHTS } \\
\text { Percentage }\end{array}$ & $\begin{array}{c}\text { Survey } \\
\text { Percentage }\end{array}$ & P-value \\
\hline Race & White & 94 & 86 & 0.0079 \\
\hline Sex & Male & 56 & 53 & 0.6357 \\
\hline Employment status & Employed & 63 & 46 & 0.0014 \\
\hline Capability to drive & Able & 97 & 91 & 0.0036 \\
\hline \multirow[t]{5}{*}{ Household income } & Under $\$ 15,000$ & 12 & 49 & $<0.0001$ \\
\hline & $\$ 15,000-\$ 27,499$ & 9 & 20 & \\
\hline & $\$ 27,500-\$ 52,499$ & 27 & 8 & \\
\hline & $\$ 52,500-\$ 89,999$ & 32 & 8 & \\
\hline & $\$ 90,000$ and over & 20 & 14 & \\
\hline \multirow[t]{7}{*}{ Household size } & 1 & 6 & 31 & $<0.0001$ \\
\hline & 2 & 50 & 28 & \\
\hline & 3 & 17 & 9 & \\
\hline & 4 & 18 & 16 & \\
\hline & 5 & 6 & 8 & \\
\hline & 6 & 2 & 0 & \\
\hline & 7 and more & 2 & 9 & \\
\hline Household vehicle & 0 & 0 & 1 & $<0.0001$ \\
\hline \multirow[t]{5}{*}{ Count } & 1 & 9 & 40 & \\
\hline & 2 & 37 & 30 & \\
\hline & 3 & 34 & 22 & \\
\hline & 4 & 11 & 7 & \\
\hline & 5 and more & 9 & 1 & \\
\hline
\end{tabular}


Table 1. Demographic Comparison between NHTS and Intercity Bus Trips (cont'd.)

\begin{tabular}{|c|c|c|c|c|}
\hline Variable Name & Category & $\begin{array}{c}\text { NHTS } \\
\text { Percentage }\end{array}$ & $\begin{array}{c}\text { Survey } \\
\text { Percentage }\end{array}$ & P-value \\
\hline \multirow{5}{*}{ Education level } & Less than high school & 7 & 7 & \multirow{5}{*}{0.0009} \\
\hline & High school or GED & 32 & 10 & \\
\hline & Some college or vocational degree & 32 & 39 & \\
\hline & Bachelor's degree & 16 & 31 & \\
\hline & Graduate or professional degree & 13 & 7 & \\
\hline \multirow{7}{*}{ Age } & Below 15 yrs & 4 & 0 & \multirow{7}{*}{0.0122} \\
\hline & $15-24$ yrs & 6 & 14 & \\
\hline & $25-34$ yrs & 10 & 13 & \\
\hline & $35-44$ yrs & 17 & 9 & \\
\hline & $45-54$ yrs & 20 & 21 & \\
\hline & $55-64$ yrs & 22 & 27 & \\
\hline & Equal to or above $65 \mathrm{yrs}$ & 21 & 15 & \\
\hline \multirow{5}{*}{ Trip purpose } & Work/school & 27 & 24 & \multirow{5}{*}{$<0.0001$} \\
\hline & Religious activity & 4 & 2 & \\
\hline & Medical/dental services & 4 & 39 & \\
\hline & Shopping/errands & 20 & 1 & \\
\hline & $\begin{array}{c}\text { Social/recreational/family/personal } \\
\text { business }\end{array}$ & 14 & 10 & \\
\hline Trip length (miles) & Mean value & 53.8 & 75.5 & $<0.0001$ \\
\hline
\end{tabular}

Note: All p-values were estimated using the Chi Squared test with the exception of trip length, evaluated with Wilcoxon Rank Sum test.

The results obtained were different from those observed in other studies, which demonstrates the importance of performing this comparison. Key results are summarized as follows:

1. Although age differences between private vehicle users and intercity bus riders are significantly different, there was no special trend to characterize the ages of intercity bus riders.

2. The race of intercity bus riders was more likely to be non-white.

3. Intercity bus riders were more likely to be unemployed.

4. Intercity bus riders were more likely to be unable to drive.

5. Intercity bus riders were more likely to be from low-income households. 
Nearly 70 percent of intercity bus riders' annual household incomes were under $\$ 27,499$, compared to 21 percent of non-riders.

6. Intercity bus riders were more likely to either live alone or have greater numbers of household members, often seven or more persons in a household.

7. Intercity bus riders were more likely to have one or fewer vehicles in the household, although there were very few zero-vehicle households in either survey. This, combined with the high number of people per household, results in higher reliance on transit service.

8. Intercity bus riders in our sample were likely to take trips for medical purposes. This could be the effect of a bias in the sampling approach, i.e., many of the bus services we surveyed fed regional medical centers.

9. Intercity bus trips were longer in distance than intercity trips by other modes.

The characteristics of intercity bus riders discovered from this survey were, to a large extent, consistent with the findings of BTS intercity bus rider study: minority, less educated, low income, and low number of personal vehicles. But they also they differed in some ways: the BTS study pointed out that most intercity bus riders are more likely to be 65 or older, while this study found no special trend on the age. This study found riders are more likely unemployed, unable to drive, live alone, or have a large household. Our study found that intercity bus rider characteristics differ compared to other studies. Different time periods, locations in which the studies were conducted, goals of intercity bus projects, and many other factors could contribute to the difference of characteristics. When system planners try to determine a demographic profile of local rider, it is important to assess local demand profiles through surveys rather than adopting the profile from other studies.

\section{Geographic Network Analysis}

The data from the on-board survey were used to profile typical intercity bus riders, focusing on characteristics we can observe in census and American Community Survey (ACS) data to identify high-demand census tracts. Five metrics were quantified for each census tract in Tennessee: non-white population density, unemployed population density, poverty-level household density, large-size household density, and low vehicle count household density. Census tracts were ranked on the five metrics. For example, the first ranking is given by non-white density-the higher the non-white population density, the higher the census tract's ranking. The five rankings were summed to get a total ranking for each census tract. 


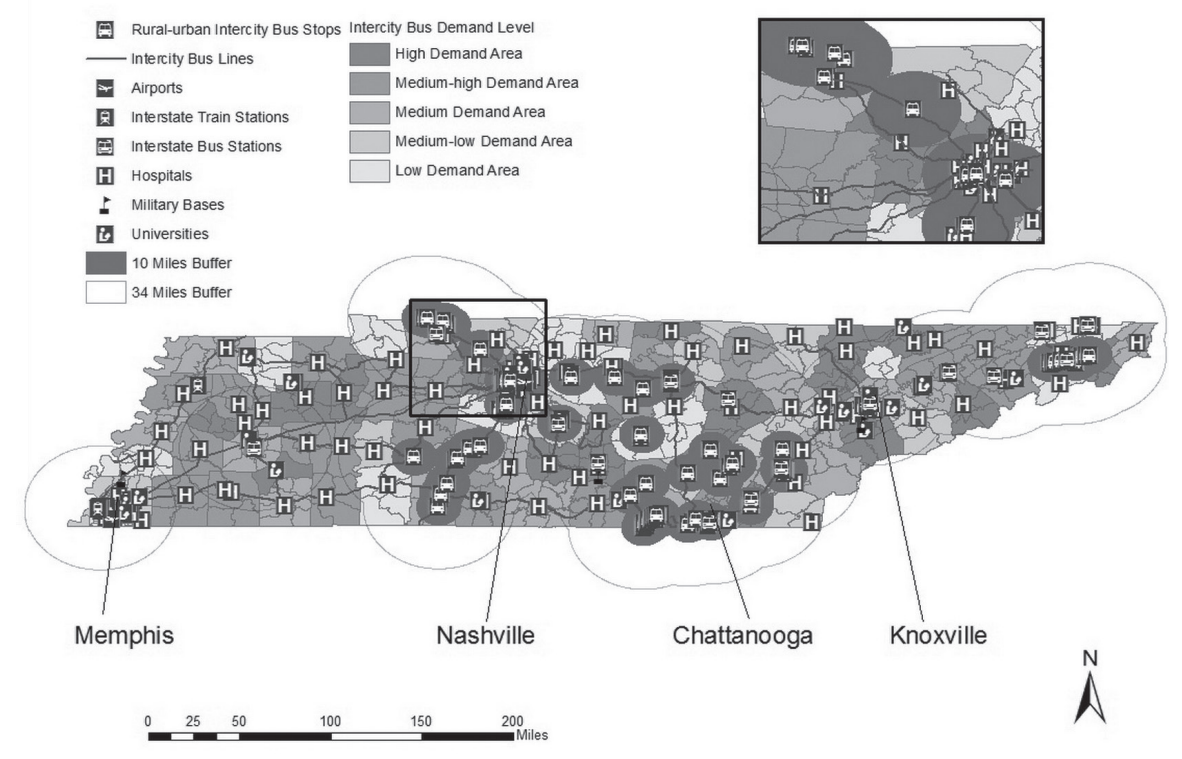

\section{Figure 2. Tennessee Intercity Bus Demand and Meaningful Destinations Map}

The intercity bus demand was divided into five levels using Natural Breaks (Jenks) algorithm: high, medium-high, medium, medium-low, and low (based on demographic rankings). The level boundaries were set where there were relatively big jumps in the rankings so as to maximize the differences between classes. This grouping level could change depending on analysis purpose or policy goal of intercity bus service coverage. Out of 1,261 census tracts, 228 were identified as the high intercity bus demand area with a total area of 7,684 square miles and 973,795 residents, approximately 18 percent of Tennessee's area and 16 percent of its population. The next highest category, medium-high demand areas, includes 296 census tracts with an area of 12,254 square miles and 1,362,653 people, which is about 29 percent of Tennessee's area and 22 percent of its population. Figure 2 shows that census tracts with similar demand levels usually are located adjacent to each other, creating the potential for intercity bus corridors.

\section{Rider and Destination Connectivity Analysis}

Six agencies provide fixed-route scheduled rural-urban intercity bus services within Tennessee, serving 87 stops. The access shed to these stops, defined as the access and egress distance, was summarized based on our survey dataset. The mean 
Euclidean access distance was 10.1 miles and the maximum was 34.0 miles. For the egress distance, almost all trips were destined for location of the bus stop (usually a major trip generator), with a mean distance of 1.2 miles and 90 percentile distance of 9.2 miles. Average egress distance was shorter than access distance because some intercity bus agencies provide stop-to-door service, transporting passengers directly to the destinations. While it is not likely that passenger origin is exactly at the starting stop, in most cases, their destination was at one of the ending stops. In these cases, their egress distance was zero.

To evaluate how well bus stops connect to riders, two buffers were made around each bus stop, one with a radius of the mean access distance value, 10 miles, and the other with a radius of the maximum value, 34 miles, as shown in Figure 2. Considering that 34 miles was the greatest distance we observed from the origin to boarding stop, the aim of the buffer with this radius was to cover all of the high and medium-high demand areas in Tennessee; the 10-mile radius buffer was meant to cover the high demand area alone.

Combining the buffers with the demographic distribution, 1,222 square miles of the 7,684 square mile high demand areas (around 16\%) were covered by the small buffer while 9,875 square miles of the 19,938 square mile medium-high and high demand areas (50\%) were covered by the large buffer. Looking at Figure 2 another way, the total area of the small buffer is 8,735 square miles, compared to 7,684 square miles of high demand area; the small buffer covers some relatively low demand areas. Similarly, the total area of the large buffer is 33,618 square miles, compared to 19,938 square miles of high and medium-high demand areas. This may imply that the bus stops are not well located to cover the high and medium-high demand areas.

Bus stops are designed to connect to riders to activity centers. Because origins and destinations often are not located in areas with high numbers of people who match intercity bus rider demographics, we determined how well these stops connect to activity centers in order to evaluate the most useful location of bus stops. One of the weaknesses of using NHTS data is that destination data are unavailable for car trips. We relied on destination information from our surveys, which was closely aligned with existing bus rider trip characteristics. This is a potential weakness since our survey was based on existing riders who are served by existing destinations, creating potential bias in our sample (i.e., we did not sample individuals whose destinations were not served by existing intercity bus). Depending on the purpose of an intercity bus program, the destination stops should connect to a 
variety of places such as hospitals, colleges and universities, airports, military bases, large employers, and so on. The Tennessee intercity bus pilot program was aimed at connecting people from rural community to urban activity centers, not specifically targeting commuting trips. We focused on medical service, urban transit centers, educational opportunities, and military bases. In the context of this study, hospitals, universities, airports, interstate bus and train stations, and military bases were regarded as meaningful destinations (see Figure 2). More specific destination studies could be warranted, depending on specific goals of the intercity bus program (e.g., displacing car trips versus providing better service to areas with unmet demand).

An intercity bus stop is considered connecting to a meaningful destination when it is located within 10 miles of the destination because it is approximately the 90 th percentile egress distance. It is also consistent with KFH Group study (KFH Group 2010). All the airports, interstate bus and train stations, hospitals, military bases, and universities in Tennessee were inventoried for this study: there are 4 commercial airports, 16 interstate bus stations, 2 interstate train stations, 156 hospitals, 3 military bases, and 67 universities and research institutes. Spatial analysis was used to determine how many stops are within the 10-mile buffer of these meaningful destinations. We found that 8 stops connect to airports, 35 stops connect to interstate bus stations, 0 stops connect to interstate train stations, 70 stops connect to hospitals, 0 stops connect to military bases, and 49 stops connect to universities and research institutes. Some of the stops connect to two or more destinations. Seventy-two stops (83\%) connect to the identified meaningful destinations, indicating the bus stops are well connected to the destinations.

In summary, intercity bus service struggles to provide service in a many-to-few origin and destination geography. Many potential origins are underserved, though the few key trip generators seem to be adequately served. To improve the existing intercity bus system, stop locations should be rearranged to better connect to the high-demand residential areas. About 15 percent of stops were found neither within high or medium-high demand areas, nor connected to any meaningful destinations. One possible improvement would be to relocate those stops to the identified high and medium-high demand areas. Some recent approaches to providing flexible deviated fixed-route service hold promise to maintain scheduled service on fixed routes while serving dispersed origins and destinations (Nourbakhsh and Ouyang 2012). 


\section{Conclusions}

Intercity bus rider characteristics and trip characteristics are different from carbased intercity or interstate trips. To evaluate these differences, we performed an onboard survey to measure Tennessee intercity bus rider characteristics and compared them with NHTS data on intercity travel. Rider characteristics were obtained from the survey and compared to previous studies. The comparison confirmed that intercity bus riders are usually non-white, less educated, and low income and have low number of personal vehicles. It also revealed that the characteristics differ between other studies, making it necessary for planners to gather information on local riders to develop regional rider profiles rather than relying on characteristics from other studies.

This research provides a new approach to identifying high intercity bus demand areas, evaluating the current and future intercity bus networks as this service continues to grow. It also introduces ways to identify the bus stops that do not have good connectivity to either origins or destinations and criteria to relocate them. The dataset used in this study is publicly available, with the exception of the intercity bus rider onboard survey data. Using the framework presented here, state transportation planners and public and private transit operators can use available data to profile areas where intercity transit could be supported by adequate ridership and identify existing intercity bus service gaps to ultimately improve the costeffectiveness of the service. Similar studies can be performed in different contexts. In those cases, local parameters should be calibrated under the proposed framework. Access mode is a key consideration and determines the coverage radius of intercity bus stops. We used a method that usually relies on auto-access to origins and walk or transit access to destinations. Based on different goals of rural-urban bus service, a unique inventory of meaningful connections should be developed. Policy coverage areas should be set based on goals of study or pre-set constraints, such as only 10 percent of the area could be regarded as high-demand area or intercity transit should cover 90 percent of high demand areas.

This paper has several limitations. First, because intercity bus service and ridership are low in Tennessee, data volume and quality presented challenges in developing robust transportation demand models. The data collection method possibly introduces some self-selection bias-that is, we surveyed existing bus riders on existing routes and projected those characteristics in the demand analysis. Nonetheless, this paper proposes one of the first contemporary frameworks to evaluate the demand and network connectivity of existing intercity bus networks to potential 
riders and destinations and has begun to address a research gap on a mode of transportation that is beginning to grow after decades of decline.

\section{Acknowledgments}

This study was funded by Tennessee Department of Transportation. The authors appreciate the support of TDOT staff, Dironna Belton, Paula Shaw, Sherri Carroll, John Reed, Stephanie Vincent, and Sandra Hoff. The authors also appreciate the support from Anchor Trailways, First Tennessee Human Resource Agency, Jarmon D \& Q Transportation, South Central Tennessee Development District, and Upper Cumberland Human Resource Agency. The views expressed in this paper are the author's only and do not necessarily reflect the views of TDOT.

\section{References}

Ashiabor, S., H. Baik, and A. Trani. 2007. Logit models for forecasting nationwide intercity travel demand in the United States. Transportation Research Record: Journal of the Transportation Research Board 2007: 1-12.

Bureau of Transportation Statistics, U.S. Department of Transportation. 1997. U.S. Profile--American Travel Survey. Washington D.C.: Research and Innovative Technology Administration.

Fravel, Frederic D., National Research Council. 2011. Toolkit for estimating demand for rural intercity bus service, TCRP report 147. Transportation Research Board, Transit Cooperative Research Program. Federal Transit Administration, and Transit Development Corporation. Washington, DC: Transportation Research Board.

J. R. Wilburn and Associates, Inc. 1981. Tennessee intercity bus study. Tennessee Department of Transportation.

KFH Group, Inc. 2010. Minnesota intercity bus network study. Minnesota Department of Transportation.

Koppelman, Frank. 1989. Multidimensional model system for intercity travel choice behavior. Transportation Research Record: Journal of the Transportation Research Board 1241: 1-8. 
Morrison, Steven, and Clifford Winston. 1985. An econometric analysis of the demand for intercity passenger transportation. Research in Transportation Economics 2: 213-237.

Nourbakhsh, Seyed Mohammad, and Yanfeng Ouyang. 2012. A structured flexible transit system for low demand areas. Transportation Research Part B: Methodological 46(1): 204-216.

Schwieterman, Joseph P., and Lauren Fischer. 2010. The intercity bus: America's fastest growing transportation mode: 2010 update on scheduled bus service. Chaddick Institute for Metropolitan Development, DePaul University.

Schwieterman, Joseph P., Lauren Fischer, Sara Smith, and Christine Towles. 2007. The return of the intercity bus: The decline and recovery of scheduled service to American cities, 1960-2007. Chicago: School of Public Service Policy Study, DePaul University, Chaddick Institute for Metropolitan Development.

Stopher, Peter R., and Joseph Prashker. 1976. Intercity passenger forecasting: The use of current travel forecasting procedures. Paper presented at Annual Meeting of the Transportation Research Forum.

\section{About the Authors}

HoNGTAI YANG (hyang17@utk.edu) is a doctoral student at University of Tennessee-Knoxville. He holds a Bachelor of Science degree in Civil Engineering from Shandong University in China. His research interests include intercity bus network design, optimization and evaluation, and traffic safety. He is a member of Institute of Transportation Engineers and American Society of Civil Engineers.

Christopher R.Cherry (cherry@utk.edu) is an Assistant Professor the Civil and Environmental Engineering Department at the University of Tennessee-Knoxville. He received a Ph.D. in Civil and Environmental Engineering from the University of California-Berkeley and a master's degree in Civil Engineering from the University of Arizona. His research interests include transportation planning and economics, sustainable transportation systems, and non-motorized transportation. 